\title{
Predictors of HIV Progression to AIDS and Mortality from AIDS and Non- AIDS Related: A Retrospective Cohort Study in Isfahan, Iran
}

Somayeh Momenyan', Motahare Yadegarfar ${ }^{2}$, Marjan Meshkati ${ }^{3}$, Katayoon Tayeri ${ }^{3}$ and Ghasem Yadegarfar $^{4 *}$

${ }^{1}$ Department of Paramedical Sciences, Shahid Beheshti University of Medical Sciences, Tehran, Iran

${ }^{2}$ Kettering General Hospital, NHS Foundation Trust, Kettering NN16 8UZ, UK

${ }^{3}$ Isfahan University of Medical Sciences, Isfahan, Iran

${ }^{4}$ Department of Epidemiology and Biostatistics, School of Public Health, Isfahan University of Medical Sciences, Isfahan, Iran

\section{Abstract}

Introduction: Few studies in Iran have explored the potential impact of factors influencing the survival time of patients with HIV and AIDS. Therefore, this study was designed to estimate the time from the HIV to AIDS progression and the time from the AIDS to the AIDS-related death and non-AIDS-related death. The prognostic factors influencing this process were also investigated.

Methods: This retrospective cohort study was conducted in Isfahan province, from 2000 to 2014. The outcome was three categories: alive or lost to follow up, and death due to AIDS related, non-AIDS-related. Cox proportional hazard and competing risks Cox model was employed to evaluate the effects of prognostic variables on the survival rate of progression to AIDS and from the AIDS to the AIDS-related death and non-AIDS-related death.

Results: We identified 307 patients, 44 were ineligible. At the end of the study period, $197(74.9 \%)$ patients were alive or lost to follow up, $28(10.6 \%)$ died from AIDS-related causes, and $38(14.4 \%)$ died from non-AIDS-related causes. Results showed there was a significant association between gender $(P=0.04)$, increase in age $(P=0.022)$, TB coinfection $(P=0.004)$, and a decreased level of $C D 4$ cell count $(P=0.012)$ with progression to AIDS. Also there was a significant association between CD4 level $(P=0.013)$ and antiretroviral therapy $(P<0.001)$ and AIDS-related deaths. There was a significant association between a level of $C D 4$ cell count $(P=0.022)$ and TB coinfection $(P=0.01)$ with non-AIDS-related deaths.

Conclusion: A substantial proportion of the patients had progressed to AIDS in the first year because they were identified very late. This source of HIV infection had the chance to transmit the infection to others. Also patients who died from AIDS-related causes of death had poorer immunological status at recruitment.

Keywords: HIV; AIDS; Survival rate; Mortality; Cohort studies; Iran

\section{Introduction}

One of the major health problems around the world is the human immunodeficiency virus (HIV). Acquired immunodeficiency syndrome (AIDS) is the advanced level of HIV infection [1]. Since the beginning of the HIV-AIDS epidemic, it has claimed approximately 36 million lives and about 75 million HIV infected people [2]. At the end of 2015 , approximately 36.7 million people were living with HIV and 2.1 million people had become newly infected with HIV globally [3]. As, there is no cure for HIV infection yet, antiretroviral treatment (ART) can effectively control the virus and return the patients to relatively healthy and productive lives [1]. This treatment has also led to better survival and improved quality of life for those who live with HIV/AIDS and has reduced viral loads, therefore potentially reducing HIV transmission. On the other hand, the primary goal of ART is to prolong lives, making HIV/AIDS a chronic illness rather than a death sentence [4]. Before introduction of ART as the mainstay of treatment for AIDS, AIDSrelated conditions were predominant, while, recently, the mortality profile is more diverse, including cardiovascular diseases (CVDs), non-AIDS-related-malignancies and other end-organ diseases such as end-stage liver and kidney diseases [5,6]. In high income countries, population-based and cohort studies have shown that, conditions such as diabetes mellitus, (CVDs), cancer, liver and kidney diseases, have become increasingly frequent in HIV-infected individuals $[7,8]$. Although HIV/AIDS-related conditions remain the most common causes of death, Non-HIV-related causes of death are now seen more than HIV-related ones in patients with $\mathrm{CD} 4^{+}$counts more than 200 cells per cubic millimeter [9]. In fact, higher survival of patients with AIDS increases, the more chance of occurrence of diseases other than those related to AIDS among HIV-infected persons. Therefore, within this shifting scenario, the surveillance of causes of mortality among HIV-infected individuals is vitally important to determine the changing epidemiology of HIV disease. This helps to find out the potential side effects of antiretroviral treatment and to improve HIV management clinically. Much research has been carried out globally to predict survival of HIV/AIDS infected individuals. Although, HIVrelated mortality and morbidity has been decreasing in recent years, a better understanding of demographic characteristics, laboratory and clinical indicators which influencing the disease progression in HIVpositive patients is required, particularly in the Eastern Mediterranean Region. However, limited investigations have been done to evaluate the progression to AIDS and to death among HIV-positive patients in this region. Few studies of AIDS-free HIV-infected individuals in Iran have explored the potential impact of factors influencing the time for progression from HIV to AIDS and from AIDS to AIDS-related death The only information comes from small, unrepresentative samples of

*Corresponding author: Ghasem Yadegarfar, Associate Professor, Department of Epidemiology and Biostatistics, School of Public Health, Isfahan University of Medical Sciences, Isfahan, Iran; Tel: 00989134127553; E-mail: g_yadegarfar@yahoo.co.uk

Received July 24, 2017; Accepted August 08, 2017; Published August 15, 2017

Citation: Momenyan S, Yadegarfar M, Meshkati M, Tayeri K, Yadegarfar G (2017) Predictors of HIV Progression to AIDS and Mortality from AIDS and Non-AIDS Related: A Retrospective Cohort Study in Isfahan, Iran. J AIDS Clin Res 8: 721. doi: 10.4172/2155-6113.1000721

Copyright: (c) 2017 Momenyan S, et al. This is an open-access article distributed under the terms of the Creative Commons Attribution License, which permits unrestricted use, distribution, and reproduction in any medium, provided the original author and source are credited. 
the population [1,10-16]. Therefore, this retrospective cohort study was designed and conducted in a high middle-income country to estimate the time from the HIV diagnosis to AIDS progression and the time from the AIDS initiation to the AIDS-related death and non-AIDSrelated death. The prognostic factors influencing this process were also investigated.

\section{Materials and Methods}

This study was a retrospective cohort study which was conducted in Isfahan province, from January 2000 to December 2014. The study population was HIV-positive people who had a medical record in the Voluntary Counseling and testing Centers. The research Council of Isfahan University of Medical Sciences approved the study with code number of 288282 . The data collection was carried out using a case record form, which was developed according to the information documented in the medical records such as demographic information (age, sex), mode of transmission, CD4 cell count, ART, co-infection with TB and causes of death. Information regarding vital status was checked up until December 312014 using the patients' medical charts, through active contact with individuals and family members. A HIVpositive case was defined as a person with HIV infection, irrespective of clinical stage confirmed by laboratory criteria according to guidelines of World Health Organization [17]. In the Islamic Republic of Iran, a case of HIV is defined as an individual by two sequential enzymelinked immunosorbent assay (ELISA) tests positive for HIV antibody confirmed by a western blot test [18]. A case of AIDS was defined as a definitive diagnosis of stage 4 conditions and/or CD4 count less than $200 / \mathrm{mm}^{3}$ of blood in a HIV-infected subject [17]. AIDS-diagnosis at baseline was defined by the occurrence of an AIDS-defining illness at or before cohort enrolment. Twenty seven patients were excluded from the survival analysis, as they had been diagnosed as AIDS cases at the time of registration at the Centers. Age at enrolment was calculated as the difference between date of birth and date of enrolment and was classified into three categories: $\leq 24,25-44$ and $\geq 45$ years. Presumed method of transmission of HIV was self-reported and defined into injection drug use (IDU), sexual (heterosexual + men who have sex with men), mother-to-child transmission and other/unknown. Baseline CD4 cell count was considered within a frame of 180 days of recruitment, and, if more than one reading was available, the value closest to the date of enrolment was selected. It was classified into four levels as $\leq 200,201-350,351-500$ and $\geq 501$ cells $/ \mathrm{mm}^{3}$. Highly active antiretroviral therapy (HAART) or in the short form ART is defined as the combination of several antiretroviral medicines used to overwhelm HIV viral replication and to lower the progress of HIV disease. In the Islamic Republic of Iran, ART is started for HIV-positive people with the following criteria: (1) stage 3 or 4 conditions; (2) CD4 count less than 350 per $\mathrm{mm} 3$; (3) coinfection with hepatitis B (HB) virus; (4) HIV-induced nephropathy; (5) having malignancy; (6) age over 60 years; or (7) HIV viral load above 100,000 copies [19]. In the analysis, the ART status was categorized as on ART and not on ART. Causes of death were classified as AIDS-related or non-AIDS related based on the presence or absence of an AIDS-defining conditions, according to the Centers for Disease Control and Prevention (CDC) Classification [20]. All deaths with unknown primary and contributing causes for which, at least, one CD4 cell count was available within 6 months before the date of death were considered as AIDS related if CD4 counts were, less than 200 cells $/ \mathrm{mm}^{3}$ and as non-AIDS related if greater than or equal to 200 cells $/ \mathrm{mm}^{3}$. If deaths that did not meet any of the these criteria, they were considered as of unknown cause [9]. We excluded 2 patients with unknown cause of death from data analysis. As a final outcome classification, individual cases were categorized into three categories: alive or lost to follow up, and death due to AIDS related, non-AIDSrelated.

\section{Statistical Analysis}

The outcomes of interest included estimating the duration of time (1) from the time of HIV diagnosis to AIDS progression, (2) from AIDS to AIDS-related death and (3) from AIDS to non-AIDSrelated death (in years). The patients who were lost to follow up and those who were alive to the end of the study period were considered censored. Descriptive statistics for background and clinical factors were compared for three groups defined as a function of vital status and classification of underlying cause of death (alive or lost to follow up, and death due to AIDS related, non-AIDS-related). Fisher's exact and Chi-squared tests were applied to evaluate differences between groups of categorical variables. The life-table technique was used to estimate the survival rate of progression to AIDS, AIDS-related death and nonAIDS-related death. Cox proportional hazard model was employed to evaluatethe effects of prognostic variables on the survival rate of progression to AIDS. To assess the factors associated with AIDS or nonAIDS related causes of death, weperformedCox proportional hazards models, adjusting for competing risks. The proportional hazards assumption was examined applying Schoenfeld residuals. Unadjusted hazard ratios (HR) and adjusted hazard ratios were calculated with 95\% confidence intervals. P-value less than 0.05 were considered as statistical significance. To illustrate the product limit estimates of the cumulative survival rate, Kaplan-Meier curves were producedamong different levels of $\mathrm{CD} 4$ to show the life time survival of the patients. Also the cumulative incidence functions for AIDS-related and non-AIDS related causes of death in a competing risks framework are reported in the figure for the whole patients based on different categories of CD4 variable. All statistical analyses were performed using Stata software, version 12.

\section{Results}

We identified 307 patients, 44 were ineligible. The analysis was based on data from the remaining 263 patients (210 men and 53 women). The mean (SD) age of the patients was 33.32 (9.24) years, with a range from 3 to 65 years. Of 263 patients infected with the HIV virus, all developed AIDS. In addition, at the end of the study period, $197(74.9 \%)$ patients were alive or lost to follow up, 28 (10.6\%) died from AIDS-related causes, and 38 (14.4\%) died from non-AIDSrelated causes. The characteristics of the study population are given in Table 1 . The majority of the HIV-infected patients were aged 25 to 44 years and male. Also $79.8 \%$ were on ART and $63.1 \%$ acquired HIV through injections. Some demographic and clinical characteristics were significantly different across the groups alive or lost to follow up, and death due to AIDS-related and non-AIDS-related causes (Table 1), such as gender distribution. Other significant differences between the groups include baseline CD4 counts $(265,172.5$ and 233 cells $/ \mathrm{mm}^{3}$, respectively), ART and TB coinfection. The probability of AIDS progression, incidence of AIDS-related death and non-AIDSrelated death are given in Table 2. The 1, 5 and 10 year probabilities of progression from HIV diagnosis to AIDS were 32\%, 75\%, and $98 \%$, respectively. The 1, 5 and 10 year probabilities of AIDS-related death after initiation of AIDS were $8 \%, 14 \%$ and $14 \%$, respectively. Also the 1,5 and 10 year probabilities of non-AIDS-related death after initiation of AIDS were $3 \%, 27 \%$ and $55.8 \%$, respectively. The effect of CD4 cell count on survival probabilities from HIV diagnosis to progression to AIDS is given in Figure 1A. There was a direct relationship between CD4 cell count and the survival probability. The higher the CD4 cell 
Citation: Momenyan S, Yadegarfar M, Meshkati M, Tayeri K, Yadegarfar G (2017) Predictors of HIV Progression to AIDS and Mortality from AIDS and Non-AIDS Related: A Retrospective Cohort Study in Isfahan, Iran. J AIDS Clin Res 8: 721. doi: 10.4172/2155-6113.1000721

Page 3 of 8

\begin{tabular}{|c|c|c|c|c|c|c|c|c|c|}
\hline \multirow[b]{2}{*}{ Variable } & \multirow[b]{2}{*}{ Category } & \multicolumn{2}{|c|}{ Alive and lost to follow up } & \multicolumn{2}{|c|}{ AIDS-related death } & \multicolumn{2}{|c|}{ Non-AIDS-related death } & \multirow[b]{2}{*}{ Total } & \multirow[b]{2}{*}{ p-value } \\
\hline & & Number & Percent & Number & Percent & Numbe & Percent & & \\
\hline \multicolumn{10}{|l|}{ Gender } \\
\hline & Male & 149 & 71 & 26 & 12.4 & 35 & 16.7 & 210 & \multirow[t]{2}{*}{0.012} \\
\hline & Female & 48 & 90.6 & 2 & 3.8 & 3 & 5.7 & 53 & \\
\hline \multicolumn{10}{|l|}{ Age } \\
\hline & Median (IQR) & \multicolumn{2}{|c|}{$32(28-38)$} & \multicolumn{2}{|c|}{$32(28-37.75)$} & \multicolumn{2}{|c|}{$33(28-41.5)$} & & \\
\hline & 45> & 25 & 75.8 & 2 & 6.1 & 6 & 18.2 & 33 & \multirow[t]{3}{*}{0.11} \\
\hline & $25-44$ & 149 & 73.4 & 22 & 10.8 & 32 & 15.8 & 203 & \\
\hline & $1-24$ & 23 & 85.2 & 4 & 14.8 & 0 & 0 & 27 & \\
\hline \multicolumn{10}{|c|}{ Tuberculosis infection } \\
\hline & Yes & 15 & 46.9 & 5 & 15.6 & 12 & 37.5 & 32 & \multirow[t]{2}{*}{$<0.001$} \\
\hline & No & 182 & 78.8 & 23 & 10 & 26 & 11.3 & 231 & \\
\hline \multicolumn{10}{|c|}{ Antiretroviral therapy } \\
\hline & Yes & 169 & 80.5 & 12 & 5.7 & 29 & 13.8 & 210 & \multirow[t]{2}{*}{$<0.001$} \\
\hline & No & 28 & 52.8 & 16 & 30.2 & 9 & 17 & 53 & \\
\hline \multicolumn{10}{|c|}{ Baseline CD4 (cells/mm³) } \\
\hline & Median (IQR) & \multicolumn{2}{|c|}{$265(130.5-417.5)$} & \multicolumn{2}{|c|}{$172.5(118.5-325.5)$} & \multicolumn{2}{|c|}{$233(100-404)$} & & \\
\hline & $0-200$ & 76 & 67.9 & 20 & 17.9 & 16 & 14.3 & 112 & \multirow[t]{4}{*}{0.038} \\
\hline & 201-350 & 54 & 87.1 & 3 & 4.8 & 5 & 8.1 & 62 & \\
\hline & $351-500$ & 27 & 77.1 & 2 & 5.7 & 6 & 17.1 & 35 & \\
\hline & $>500$ & 37 & 80.4 & 2 & 4.3 & 7 & 15.2 & 46 & \\
\hline \multicolumn{10}{|c|}{ Mode of transmission } \\
\hline & Injection & 115 & 69.3 & 22 & 13.3 & 29 & 17.5 & 166 & \multirow[t]{4}{*}{0.078} \\
\hline & Mother to child & 4 & 80 & 1 & 20 & 0 & 0 & 5 & \\
\hline & Others/unknown & 12 & 80 & 2 & 13.3 & 1 & 6.7 & 15 & \\
\hline & Sexual & 66 & 85.7 & 3 & 3.9 & 8 & 10.4 & 77 & \\
\hline
\end{tabular}

Table 1: Demographic and clinical characteristics of the study population by vital status and cause of death.
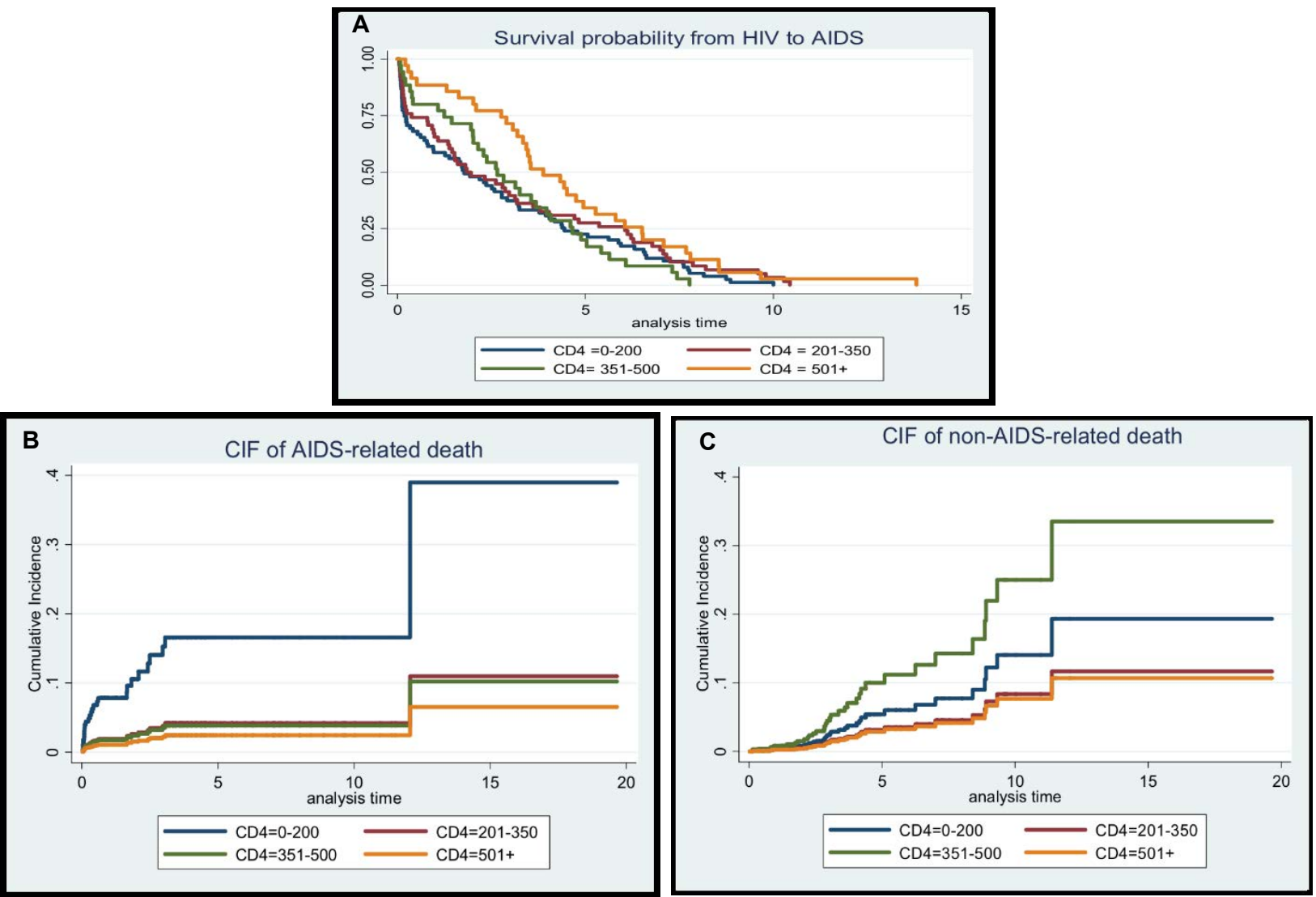

Figure 1: The effect of CD4 cell count on survival probability from diagnosis of HIV to progression to AIDS and cumulative incidence functions from AIDS to AIDSrelated, non-AIDS related death. 
Page 4 of 8

\begin{tabular}{|c|c|c|c|c|c|c|}
\hline Survival time (years) & Total & Event & Censored & Probability & SE & $95 \% \mathrm{Cl}$ \\
\hline \multicolumn{7}{|c|}{ From HIV to AIDS } \\
\hline 1 & 236 & 76 & 0 & 0.32 & 0.03 & $0.26-0.038$ \\
\hline 2 & 160 & 29 & 0 & 0.44 & 0.03 & $0.38-0.51$ \\
\hline 3 & 131 & 31 & 0 & 0.57 & 0.03 & $0.51-0.63$ \\
\hline 4 & 100 & 23 & 0 & 0.67 & 0.03 & $0.61-0.73$ \\
\hline 5 & 77 & 20 & 0 & 0.75 & 0.02 & $0.70-0.81$ \\
\hline 6 & 57 & 13 & 0 & 0.81 & 0.02 & $0.76-0.86$ \\
\hline 7 & 44 & 16 & 0 & 0.88 & 0.02 & $0.83-0.91$ \\
\hline 8 & 28 & 15 & 0 & 0.94 & 0.01 & $0.91-0.96$ \\
\hline 9 & 13 & 6 & 0 & 0.97 & 0.01 & $0.94-0.98$ \\
\hline 10 & 7 & 4 & 0 & 0.98 & 0.007 & $0.96-0.99$ \\
\hline 11 & 3 & 2 & 0 & 0.99 & 0.004 & $0.97-0.99$ \\
\hline $13+$ & 1 & 0 & 0 & 1.00 & 0.000 & $0.00-0.00$ \\
\hline \multicolumn{7}{|c|}{ From AIDS to AIDS-related death } \\
\hline 1 & 263 & 19 & 56 & 0.080 & 0.01 & $0.05-0.12$ \\
\hline 2 & 188 & 3 & 45 & 0.097 & 0.01 & $0.06-0.14$ \\
\hline 3 & 140 & 4 & 44 & 0.128 & 0.02 & $0.08-0.18$ \\
\hline 4 & 92 & 1 & 40 & 0.140 & 0.02 & $0.09-0.20$ \\
\hline 5 & 51 & 0 & 21 & 0.140 & 0.02 & $0.09-0.20$ \\
\hline 6 & 30 & 0 & 5 & 0.140 & 0.02 & $0.09-0.20$ \\
\hline 7 & 25 & 0 & 4 & 0.140 & 0.02 & $0.09-0.20$ \\
\hline 8 & 21 & 0 & 6 & 0.140 & 0.02 & $0.09-0.20$ \\
\hline 9 & 15 & 0 & 5 & 0.140 & 0.02 & $0.09-0.20$ \\
\hline 10 & 10 & 0 & 4 & 0.140 & 0.02 & $0.09-0.20$ \\
\hline 11 & 6 & 0 & 2 & 0.140 & 0.02 & $0.09-0.20$ \\
\hline 12 & 4 & 0 & 2 & 0.140 & 0.02 & $0.09-0.20$ \\
\hline 13 & 2 & 1 & 0 & 0.570 & 0.30 & $0.15-0.98$ \\
\hline $20+$ & 1 & 0 & 1 & 0.570 & 0.30 & $0.15-0.98$ \\
\hline \multicolumn{7}{|c|}{ From AIDS to Non-AIDS-related death } \\
\hline 1 & 263 & 7 & 68 & 0.030 & 0.011 & $0.01-0.06$ \\
\hline 2 & 188 & 4 & 44 & 0.053 & 0.016 & $0.03-0.09$ \\
\hline 3 & 140 & 9 & 39 & 0.124 & 0.027 & $0.08-0.18$ \\
\hline 4 & 92 & 6 & 35 & 0.195 & 0.037 & $0.13-0.28$ \\
\hline 5 & 51 & 4 & 17 & 0.270 & 0.049 & $0.18-0.38$ \\
\hline 6 & 30 & 1 & 4 & 0.296 & 0.054 & $0.20-0.41$ \\
\hline 7 & 25 & 1 & 3 & 0.328 & 0.059 & $0.22-0.45$ \\
\hline 8 & 21 & 1 & 5 & 0.363 & 0.066 & $0.24-0.50$ \\
\hline 9 & 15 & 3 & 2 & 0.499 & 0.087 & $0.34-0.67$ \\
\hline 10 & 10 & 1 & 3 & 0.558 & 0.094 & $0.38-0.74$ \\
\hline 11 & 6 & 0 & 2 & 0.558 & 0.094 & $0.38-0.74$ \\
\hline 12 & 4 & 1 & 1 & 0.684 & 0.126 & $0.44-0.89$ \\
\hline 13 & 2 & 0 & 1 & 0.684 & 0.126 & $0.44-0.89$ \\
\hline $20+$ & 1 & 0 & 1 & 0.684 & 0.126 & $0.44-0.89$ \\
\hline
\end{tabular}

Table 2: The duration of times for progression from HIV infection to AIDS and from AIDS to AIDS and Non-AIDS related death using life table.

count, the higher the survival probability. The cumulative incidence functions for AIDS-related and non-AIDS-related deaths are shown in the Figures $1 \mathrm{~B}$ and $1 \mathrm{C}$, respectively for the entire patients based on CD4 variable categories. The shape of the curves for AIDS-related and nonAIDS-related causes of death clearly show that the lowest acceleration of risk accumulation occurred in the group with highest CD4. The effect of all predictors on progression to AIDS, AIDS-related death and non-AIDS-related death is given in Tables 3-5, respectively. Based on the adjusted HR estimated by the Cox proportional hazard model, there was a significant association between predictors and progression to AIDS: gender $(\mathrm{P}=0.04)$, increase in age $(\mathrm{P}=0.022)$, $\mathrm{TB}$ coinfection $(\mathrm{P}=0.004)$ and a decreased level of $\mathrm{CD} 4$ cell count $(\mathrm{P}=0.012)$. Based on the adjusted HR estimated by the competing risks Cox model, there was a significant association between some predictors and AIDS-related deaths: $\mathrm{CD} 4$ level $(\mathrm{P}=0.013)$ and antiretroviral therapy $(\mathrm{P}<0.001)$. Also there was a significant association between a level of $\mathrm{CD} 4$ cell count $(\mathrm{P}=0.022)$ and $\mathrm{TB}$ coinfection $(\mathrm{P}=0.01)$ with non-AIDS-related deaths. Lower CD4 cell counts at baseline significantly increased the hazard of AIDS-related and non-AIDS-related causes of death, although the magnitude of the HR estimates was much higher for AIDS-related causes of death. The hazard for AIDS-related death increased from significant hazard ration of 8.83 for those who did not received ART compared to those who received ART. The hazard for non-AIDS related causes of death, increased from a significant hazard ratio of 2.75 for those who have TB coinfection compared to those who did not have TB coinfection. For non-AIDS related death hazard ration of age variable 
Citation: Momenyan S, Yadegarfar M, Meshkati M, Tayeri K, Yadegarfar G (2017) Predictors of HIV Progression to AIDS and Mortality from AIDS and Non-AIDS Related: A Retrospective Cohort Study in Isfahan, Iran. J AIDS Clin Res 8: 721. doi: 10.4172/2155-6113.1000721

Page 5 of 8

\begin{tabular}{|c|c|c|c|c|c|}
\hline Variables & Category & $\begin{array}{c}\text { Unadjusted HR } \\
(95 \% \mathrm{Cl})\end{array}$ & P-value & $\begin{array}{l}\text { Adjusted HR } \\
(95 \% \mathrm{Cl})\end{array}$ & P-value \\
\hline \multicolumn{6}{|l|}{ Gender } \\
\hline & Male & $0.68(0.48-0.96)$ & 0.02 & $0.62(0.38-0.97)$ & 0.04 \\
\hline & Female & \multicolumn{4}{|c|}{ Reference } \\
\hline \multicolumn{6}{|l|}{ Age } \\
\hline & 45> & $1.69(0.96-2.98)$ & 0.06 & $1.78(0.91-3.50)$ & 0.09 \\
\hline & $25-44$ & $1.44(0.95-2.18)$ & 0.08 & $1.79(1.08-2.96)$ & 0.022 \\
\hline & $1-24$ & \multicolumn{4}{|c|}{ Reference } \\
\hline \multicolumn{6}{|c|}{ Tuberculosis infection } \\
\hline & Yes & $1.81(1.23-2.67)$ & 0.003 & $2.011(1.25-3.23)$ & 0.004 \\
\hline & No & \multicolumn{4}{|c|}{ Reference } \\
\hline \multicolumn{6}{|c|}{ Antiretroviral therapy } \\
\hline & No & $1.07(0.79-1.45)$ & 0.64 & $0.96(0.64-1.42)$ & 0.84 \\
\hline & yes & \multicolumn{4}{|c|}{ Reference } \\
\hline \multicolumn{6}{|c|}{ Baseline CD4 (cells $/ \mathrm{mm}^{3}$ ) } \\
\hline & $0-200$ & $1.64(1.09-2.47)$ & 0.01 & $1.72(1.12-2.62)$ & 0.012 \\
\hline & 201-350 & $1.36(0.89-2.09)$ & 0.14 & $1.25(0.80-1.93)$ & 0.31 \\
\hline & $351-500$ & $1.61(1.00-2.60)$ & 0.04 & $1.34(0.80-2.23)$ & 0.25 \\
\hline & $>500$ & \multicolumn{4}{|c|}{ Reference } \\
\hline \multicolumn{6}{|c|}{ Mode of transmission } \\
\hline & Injection & $0.68(0.50-0.92)$ & 0.01 & $0.76(0.50-1.15)$ & 0.20 \\
\hline & Mother to child & $1.66(0.59-4.60)$ & 0.32 & $2.25(0.67-7.51)$ & 0.18 \\
\hline & Others/unknown & $0.73(0.40-1.34)$ & 0.31 & $0.68(0.33-1.38)$ & 0.29 \\
\hline & Sexual & \multicolumn{4}{|c|}{ Reference } \\
\hline
\end{tabular}

Table 3: The effect of predictors on the duration of time from HIV diagnosis to AIDS progression using univariate and multivariate hazard ratio (HR).

\begin{tabular}{|c|c|c|c|c|c|}
\hline Variables & Category & $\begin{array}{c}\text { Unadjusted HR } \\
(95 \% \mathrm{Cl})\end{array}$ & P-value & $\begin{array}{l}\text { Adjusted HR } \\
(95 \% \mathrm{Cl})\end{array}$ & P-value \\
\hline \multicolumn{6}{|l|}{ Gender } \\
\hline & Male & 3.17 (0.74-13.57) & 0.11 & $1.41(0.32-6.31)$ & 0.62 \\
\hline & Female & \multicolumn{4}{|c|}{ Reference } \\
\hline \multicolumn{6}{|l|}{ Age } \\
\hline & 45> & $0.33(0.05-1.84)$ & 0.20 & $0.81(0.09-7.10)$ & 0.85 \\
\hline & $25-44$ & $0.62(0.21-1.76)$ & 0.37 & $1.20(0.24-5.96)$ & 0.82 \\
\hline & $1-24$ & \multicolumn{4}{|c|}{ Reference } \\
\hline \multicolumn{6}{|c|}{ Tuberculosis infection } \\
\hline & Yes & $1.49(0.55-3.96)$ & 0.42 & $0.89(0.20-3.93)$ & 0.88 \\
\hline & No & \multicolumn{4}{|c|}{ Reference } \\
\hline \multicolumn{6}{|c|}{ Antiretroviral therapy } \\
\hline & No & $6.87(3.24-14.51)$ & $<0.001$ & $8.83(3.79-20.55)$ & $<0.001$ \\
\hline & yes & \multicolumn{4}{|c|}{ Reference } \\
\hline \multicolumn{6}{|c|}{ Baseline CD4 (cells/mm³) } \\
\hline & $0-200$ & $4.93(1.18-20.59)$ & 0.028 & $7.26(1.51-34.76)$ & 0.013 \\
\hline & 201-350 & $1.26(0.22-7.31)$ & 0.79 & $1.71(0.24-11.37)$ & 0.56 \\
\hline & $351-500$ & $1.51(0.22-10.42)$ & 0.67 & $1.57(0.22-11.25)$ & 0.64 \\
\hline & $>500$ & \multicolumn{4}{|c|}{ Reference } \\
\hline \multicolumn{6}{|c|}{ Mode of transmission } \\
\hline & Injection & $3.80(1.11-13.01)$ & 0.033 & $2.32(0.66-8.15)$ & 0.18 \\
\hline & Mother to child & $5.55(0.63-48.82)$ & 0.122 & $9.39(0.83-105.96)$ & 0.070 \\
\hline & Others/unknown & $3.61(0.62-20.96)$ & 0.153 & $2.63(0.39-17.34)$ & 0.31 \\
\hline & Sexual & \multicolumn{4}{|c|}{ Reference } \\
\hline
\end{tabular}

Table 4: The effect of predictors on the duration of time from AIDS to AIDS-related death using univariate and multivariate hazard ratio (HR).

could not be calculated because of insufficient number of non-AIDS related death in age categories.

\section{Discussion}

The present paperis based on a retrospective cohort of HIV/AIDS patients registered at different Voluntary Counseling and testing Centers during 2000-2014 in Isfahan, Iran. At the end of follow-up, $74.9 \%$ patients were alive or lost to follow up, $10.6 \%$ died from AIDSrelated and $14.4 \%$ died from non-AIDS-related causes. We showed that $63.1 \%$ of patients acquired HIV through injection mode of transmission. 
Page 6 of 8

\begin{tabular}{|c|c|c|c|c|c|}
\hline Variables & Category & $\begin{array}{l}\text { Unadjusted HR } \\
\quad(95 \% \mathrm{Cl})\end{array}$ & P-value & $\begin{array}{l}\text { Adjusted HR } \\
(95 \% \mathrm{Cl})\end{array}$ & P-value \\
\hline \multicolumn{6}{|l|}{ Gender } \\
\hline & Male & $2.39(0.74-7.68)$ & 0.14 & $1.11(0.23-5.49)$ & 0.89 \\
\hline & Female & \multicolumn{4}{|c|}{ Reference } \\
\hline \multicolumn{6}{|l|}{ Age } \\
\hline & $45>$ & - & - & - & - \\
\hline & $25-44$ & - & - & - & - \\
\hline & $1-24$ & \multicolumn{4}{|c|}{ Reference } \\
\hline \multicolumn{6}{|c|}{ Tuberculosis infection } \\
\hline & Yes & $3.08(1.61-5.89)$ & 0.001 & $2.75(1.28-5.93)$ & 0.01 \\
\hline & No & \multicolumn{4}{|c|}{ Reference } \\
\hline \multicolumn{6}{|c|}{ Antiretroviral therapy } \\
\hline & No & $1.20(0.54-2.65)$ & 0.65 & $0.79(0.34-1.82)$ & 0.59 \\
\hline & yes & \multicolumn{4}{|c|}{ Reference } \\
\hline \multicolumn{6}{|c|}{ Baseline CD4 (cells/mm³) } \\
\hline & $0-200$ & $1.26(0.54-2.96)$ & 0.58 & $1.89(0.80-4.46)$ & 0.14 \\
\hline & 201-350 & $0.81(0.25-2.54)$ & 0.71 & $1.09(0.36-3.34)$ & 0.87 \\
\hline & $351-500$ & $1.78(0.63-5.01)$ & 0.27 & $3.60(1.20-10.83)$ & 0.022 \\
\hline & $>500$ & \multicolumn{4}{|c|}{ Reference } \\
\hline \multicolumn{6}{|c|}{ Mode of transmission } \\
\hline & Injection & $2.80(1.11-13.01)$ & 0.025 & $3.10(0.92-10.38)$ & 0.18 \\
\hline & Mother to child & - & - & $0.49(0.05-4.86)$ & 0.070 \\
\hline & Others/unknown & $0.78(0.10-5.83)$ & 0.81 & $0.66(0.06-7.01)$ & 0.31 \\
\hline & Sexual & \multicolumn{4}{|c|}{ Reference } \\
\hline
\end{tabular}

Table 5: The effect of predictors on the duration of time from AIDS to Non-AIDS-related death using univariate and multivariate hazard ratio (HR).

Access to sterile injecting equipment, methadone maintenance therapy and outreach services can successfully decrease the risk of HIV transmission among IDUs [21]. Also, screening programs can be conducted by the Voluntary Counseling and Testing Centers of Iran among injection drug users. This can lead to decrease time interval between the time of initiation of HIV infection and the time of diagnosis. Therefore, HIV-positive patients have had the opportunity to be treated and returned to relatively healthy and productive lives. Our findings showed, the 1 and 10 year probabilities of progression from HIV diagnosis to AIDS were $32 \%$ and $98 \%$, respectively. The 1 and 10 year probabilities of AIDS-related death after initiation of AIDS were $8 \%$ and $14 \%$, respectively. The 1 and 10 year probabilities of non-AIDSrelated death after initiation of AIDS were 3\% and 55.8\%, respectively. A few studies have reported the duration of time for progression from HIV infection to AIDS and from AIDS to death. Poorolajal et al. conducted a retrospective cohort study in Tehran, Iran and reported that the 1 and 10 year probabilities of progression from HIV diagnosis to AIDS were $45.0 \%$ and $90.4 \%$, respectively. Also they showed that the 1 and 10 year probabilities of AIDS-related death after initiation of AIDS were $17.2 \%$ and $39.2 \%$, respectively [1]. Another study in Hamadan, Iran was performed by Mirzaei et al. Based on this study, 1 and 10 year survival rates from HIV to AIDS were $89 \%$ and $30 \%$, respectively. One year and five year survival rates from AIDS to death were $76 \%$ and $46 \%$, respectively [12]. A prospective cohort study which was carried out by Maruza et al. in 2012 in Brazil showed that the probability of 30 months survival among HIV-infected patients was $70 \%$ [22]. Spagnuoloet al. performed a retrospective cohort study in Italy in 2012 and showed that 10 year survival of HIV infected subjects with non-AIDS-defining malignancies was $44.7 \%$ [23]. Based on our results, a substantial proportion (32.0\%) of the patients had progressed to AIDS in the first year. The reason for this aggregation of the events in the first year could be delayed diagnosis and other reasons such as poor adherence to ART regimen combined with other co-morbid infections and low CD4 cell count [24]. Of the 263 HIV-infected patients, 27 presented with AIDS when they registered as patients at the Centers. This indicates a substantial gap between the time of initiation of HIV infection and the time of diagnosis (i.e., left censoring). This means that HIV-positive patients have had the opportunity to transfer the infection between subjects with high-risk behaviors such as intravenous drug addicts and sex workers. According to the existing evidence, a considerable proportion of HIV-positive patients do not take an action for HIV testing until late in infection. Late presentation for HIV testing means that chances for harm reduction are missed [25]. Approximately, $54-70 \%$ of the sexually transmitted HIV stem from the HIV-positive individuals who do not know about their HIV-positive status [26]. We indicated that patients who died from AIDS-related causes of death had poorer immunological status at recruitment in comparison with those who remained alive or died of non-AIDS-related causes of death. Median CD4 cell counts at baseline for patients who died of AIDSrelated causes were 172.5 cells $/ \mathrm{mm}^{3}$ against to 233 cells $/ \mathrm{mm}^{3}$ for patients who died of non-AIDS related causes. We presented the effect of several predictors on the duration of time from HIV diagnosis to AIDS progression and from AIDS initiation to AIDS-related death and non-AIDS-related death using univariate and multivariate analysis. Gender was associated with progression to AIDS; the hazard of AIDS among women was significantly higher than among men, as previously reported by others $[1,12,27]$. Also the survival rate from AIDS to death was not any more significant as previously stated by others [4,13,22,27]. However, based on the study carried out by Mirzaei et al., the survival rate from AIDS to death was higher for women than in men [12]. They reported two explanations for the difference between the two genders. First, sample size of women was very small and therefore the difference may be just due to random error. Second the discrepancy may only be attributed to more censorship that occurred among men. TB is a leading preventable cause of death among people living with HIV. We showed that HIV positive individuals who were co-infected with TB had two- 
times higher risk of progression to AIDS in comparison with those who infected with HIV alone. Also hazard ratio of non-AIDS-related death was 2.7 fold higher for subjects co-infected with TB compared to those without TB but it was not associated with AIDS-related death because of small sample size of AIDS-related death. Mirzaei et al. showed a strong relationship between co-infection with $\mathrm{TB}$ and progression to AIDS [12]. Lopez-Gatell et al. indicated that the hazard ratio of AIDSrelated death was 2.4 times higher for individuals co-infected with $\mathrm{TB}$ compared to those without TB [28]. This evidence showed the importance of treatment of TB in HIV infected people. In 2004, the World Health Organization (WHO) published an interim strategy on collaborative TB/HIV activities and underlined on three distinct aims: (a) forming and strengthening mechanisms for combined delivery of TB and HIV services; (b) decreasing the burden of TB among people living with HIV and beginning early antiretroviral therapy and (c) decreasing the burden of HIV among people with possible TB and diagnosed TB [29]. According to our results, patients aged 25-44 years were at about two fold higher risk of AIDS compared to patients aged $\leq$ 24 years. The epidemiological studies have revealed that patients aged 50 years or over are at a higher risk of progression to AIDS in comparison with younger patients $[1,4]$. In a regression model for the hazards subdistribution adjusted for possible confounders, although baseline age was not significantly associated with risk for AIDS-related-death and non-AIDS-related death. On the other hand, baseline age had no significant effect on the risk for death because median age at baseline for patients who died of AIDS-related causes was 32 as opposed to 33 for patients who died of non-AIDS related causes. These findings are in agreement with the recent description of HIV cohorts [1,27]. We showed that patients who did not receive ART had about eight-fold increased risk of AIDS-related death in comparison with those patients whom treated by ART. We also demonstrated that ART was not associated with risk of non-AIDS-related death. Observational studies performed in both resource-limited and high-income countries have demonstrated that ART is associated with significant decreases in mortality rates with a range of 54-92\%. Evidence based on randomized clinical trials has revealed that early initiation of ART during antituberculosis treatment is associated with reduction in mortality rates, particularly in patients with profound immune destruction. A clinical trial carried out in Cambodia, which studied $661 \mathrm{HIV}$-infected TB patients with a median CD4 count of 25 cells $/ \mathrm{mm}^{3}$, indicated that mortality was reduced by $38 \%$ when ART was begun two weeks versus eight weeks after onset of ART [30]. We suggest that the screening programs be performed regularly in individual with high risk because there will be opportunity for HIV-positive patients to receive effective ART. Furthermore, the number of centers providing these treatments should be increased.

According to our adjusted analysis, we found that lower CD4 cell counts were significantly associated with progression to AIDS. Also reductions in levels of CD4 cell counts increased the hazard of death from AIDS-related causes and non-AIDS-related causes. In other words, CD4 cell count plays an important role in the incidence of AIDS and death. Furthermore, epidemiological studies have shown that the risk of HIV/TB coinfection increases as the CD4 cell count decreases $[31,32]$. Although plenty of research is available globally regarding survival of HIV/AIDS patients. Further research is still required in Iranian patient populations. Our study has strengths and limitations that are worth mentioning. Strength was that all efforts were made to verify each patient's vital status, including the verification of charts, active contact with individuals or family members and linkage with the Isfahan Mortality database. However, it is possible the complete ascertainment of deaths was not attained. Even though vital status was still missing for 10 patients lost to follow-up, we believe that this has not affected our results as these patients tended to be younger and to have higher CD4 cell counts than patients remaining in the cohort. Thus, if these losses to follow-up were because of death, the likely cause is a non-AIDS-related condition. The first pitfall, survival analysis requires reliable sources of data gained from prospective cohort studies while we carried out a retrospective design and used data recorded by registry centers. The quality and precision of the estimations and associations primarily depend on the quality of the recorded data, and we were unable to verify the accuracy of the data. This concern may raise the possibility of information bias. Second, we used a few background and clinical characteristics and therefore, we could not take into consideration all the potential confounders such as viral load and co-morbid status that could have influenced the survival of patients. The third pitfall was related to the missing data for different covariates as well as date of AIDS and date of death. Forth, in order to estimate the time of AIDS progression, AIDS-related deaths and non-AIDSrelated deaths, we used the date of diagnosis of HIV while a substantial number of patients were not diagnosed until late in infection. This might result in under-estimating the actual survival probability from the beginningof HIV infection to AIDS progression. Also, continuous follow-up is needed to determine the exact time of manifest of AIDS. Since some individuals were not seen regularly, the exact time of AIDS onset might have been recorded later than the real time. This issue might lead to overestimation of the actual survival time. The fifth pitfall refers to how representative the study population is of the HIV/AIDS patients cared for at other centers in Iran. We studied relatively small number of deaths $(n=66)$, which made some of the models we used under powered for associations.

\section{Conclusion}

Our retrospective cohort study showed the 1 and 10 year probabilities of progression from HIV diagnosis to AIDS were $32 \%$ and 98\%, respectively; the same probabilities of AIDS-related death after initiation of AIDS were $8 \%$ and $14 \%$; and for non-AIDS-related death after initiation of AIDS were $3 \%$ and $55.8 \%$, respectively. A substantial proportion $(32.0 \%)$ of the patients had progressed to AIDS in the first year. Poor immunological status at enrolment of patients, gender, coinfection with $\mathrm{TB}$, age and treating with ART were strong independent predictors of AIDS-related causes of death and/or progression to AIDS. Patients who died from AIDS-related causes of death had poorer immunological status at recruitment. The hazard of AIDS among women was significantly higher than among men. The HIV positive individuals who were co-infected with TB had two-times higher risk of progression to AIDS. The older patients had the higher risk of progression to AIDS. The patients who did not receive ART had about eight-fold higher risk of AIDS-related death in comparison with those patients whom treated by ART.

\section{Acknowledgement}

The authors wish to thank staff of Voluntary Counseling and testing Centers for recording data and their collaboration with this study. We are also so grateful Research Department of Isfahan University of Medical Sciences for supporting this work.

\section{References}

1. Poorolajal J, Molaeipoor L, Mohraz M, Mahjub H, Ardekani MT, et al. (2015) Predictors of progression to AIDS and mortality post-HIV infection: A long-term retrospective cohort study. AIDS Care 27: 1205-1212.

2. http://www.who.int/mediacentre/factsheets/fs360/en/

3. www.who.int/mediacentre/factsheets/fs360/en/ 
Citation: Momenyan S, Yadegarfar M, Meshkati M, Tayeri K, Yadegarfar G (2017) Predictors of HIV Progression to AIDS and Mortality from AIDS and Non-AIDS Related: A Retrospective Cohort Study in Isfahan, Iran. J AIDS Clin Res 8: 721. doi: 10.4172/2155-6113.1000721

4. Bajpai RC, Raj P, Jha UM, Chaturvedi HK, Pandey A (2014) Demographic correlates of survival in adult HIV patients registered at ART centers in Andhra Pradesh, India: A retrospective cohort study. Public Health Res 4: 31-38.

5. Crum NF, Riffenburgh RH, Wegner S, Agan BK, Tasker SA, et al. (2006) Comparisons of causes of death and mortality rates among HIV-infected persons: Analysis of the pre-, early and late HAART (highly active antiretroviral therapy) eras. J Acquir Immune Defic Syndr 41: 194-200.

6. Pacheco AG, Tuboi SH, Faulhaber JC, Harrison LH, Schechter M (2008) Increase in non-AIDS related conditions as causes of death among HIVinfected individuals in the HAART era in Brazil. PLoS ONE 3: e1531.

7. Novoa AM, de Olalla PG, Clos R, Orcau A, Rodríguez-Sanz M, et al. (2008) Increase in the non-HIV-related deaths among AIDS cases in the HAART era. Curr HIV Res 6: 77-81.

8. Lewden C, May T, Rosenthal E, Burty C, Bonnet F, et al. (2008) Changes in causes of death among adults infected by HIV between 2000 and 2005 : The "Mortalite 2000 and 2005" surveys (ANRS EN19 and Mortavic). J Acquir Immune Defic Syndr 48: 590-598.

9. Pacheco AG, Tuboi SH, May SB, Moreira LF, Ramadas L, et al. (2009) Temporal changes in causes of death among HIV-infected patients in the HAART era in Rio de Janeiro, Brazil. J Acquir Immune Defic Syndr 51: 624-630.

10. Fallahzadeh H, Morowatisharifabad M, Ehrampoosh MH (2009) HIVIAIDS epidemic features and trends in Iran, 1986-2006. AIDS Behav 13: 297-302.

11. Haghdoost AA, Mostafavi E, Mirzazadeh A, Navadeh S, Feizzadeh A, et al. (2011) Modelling of HIVIAIDS in Iran up to 2014. J AIDS HIV Res 3: 231-239.

12. Mirzaei M, Poorolajal J, Khazaei S, Saatchi M (2013) Survival rate of AIDS disease and mortality in HIV-infected patients in Hamadan, Iran: A registrybased retrospective cohort study (1997-2011). Int J STD AIDS 24: 859-866.

13. Tabarsi P, Chitsaz E, Moradi A, Baghaei P, Farnia P, et al. (2012) Treatment outcome, mortality and their predictors among HIV-associated tuberculosis patients. Int J STD AIDS 23: e1-e4.

14. Zamani S, Kihara M, Gouya MM, Vazirian M, Nassirimanesh B et al. (2006) High prevalence of HIV infection associated with incarceration among community-based injecting drug users in Tehran, Iran. J Acquir Immune Defic Syndr 42: 342-346.

15. Rezaianzadeh A, Hasanzadeh J, Alipour A, Davarpanah MA, Rajaeifard A, et al. (2012) Impact of hepatitis C on survival of HIV-infected individuals in Shiraz; South of Iran. Hepat Mon 12: 106-111.

16. Razani N, Mohraz M, Kheirandish P, Malekinejad M, Malekafzali H, et al. (2007) HIV risk behavior among injection drug users in Tehran, Iran. Addiction 102: $1472-1482$.

17. Organization WH (2007) WHO case definitions of HIV for surveillance and revised clinical staging and immunological classification of HIV-related disease in adults and children.
18. Radfar S, Taheri K, Namdari Tabar H (2009) Practical guidelines on how to provide consulting services in behavioral disorders centers. Ministry of Health and Medical Education, Tehran.

19. Education MoHaM (2011) Evaluation of patients with HIVIAIDS and antiretroviral therapy in adults and adolescents.

20. Ward M, Buehler MJW, Jaffe MHW, Berkelman RL (1993) 1993 revised classification system for HIV infection and expanded surveillance case definition for AIDS among adolescents and adults.

21. De Cock KM, Jaffe HW, Curran JW (2012) The evolving epidemiology of HIV AIDS. AIDS 26: 1205-1213.

22. Maruza M, Albuquerque M, Braga MC, Barbosa M, Byington R, et al. (2012) Survival of HIV-infected patients after starting tuberculosis treatment: A prospective cohort study. Int J Tuberc Lung Dis 16: 618-624.

23. Spagnuolo V, Galli L, Salpietro S, Gianotti N, Guffanti M, et al. (2012) Ten year survival among HIV-1-infected subjects with AIDS or non-AIDS-defining malignancies. Int J Cancer 130: 2990-2996.

24. Rai S, Mahapatra B, Sircar S, Raj PY, Venkatesh S, et al. (2013) Adherence to antiretroviral therapy and its effect on survival of HIV-infected individuals in Jharkhand, India. PLoS ONE 8: e66860.

25. Girardi E, Sabin CA, Antonella d'Arminio Monforte M (2007) Late diagnosis of HIV infection: Epidemiological features, consequences and strategies to encourage earlier testing. J Acquir Immune Defic Syndr 46: S3-S8.

26. Marks G, Crepaz N, Janssen RS (2006) Estimating sexual transmission of HIV from persons aware and unaware that they are infected with the virus in the USA. Aids 20: 1447-1450.

27. Grinsztejn B, Luz PM, Pacheco AG, Santos DV, Velasque L, et al. (2013) Changing mortality profile among HIV-infected patients in Rio de Janeiro, Brazil: Shifting from AIDS to non-AIDS related conditions in the HAART era PLoS ONE 8: e59768.

28. López-Gatell H, Cole SR, Margolick JB, Witt MD, Martinson J, et al. (2008) Effect of tuberculosis on the survival of HIV-infected men in a country with low tuberculosis incidence. AIDS 22: 1869-1873.

29. Organization WH (2012) WHO policy on collaborativeTB/HIV activities: Guidelines for national programmes and other stakeholders.

30. Blanc F-X, Sok T, Laureillard D, Borand L, Rekacewicz C, et al. (2011) Earlier versus later start of antiretroviral therapy in HIV-infected adults with tuberculosis. N Engl J Med 365: 1471-1481.

31. Hwang JH, Choe PG, Kim NH, Bang JH, Song K-H, et al. (2013) Incidence and risk factors of tuberculosis in patients with human immunodeficiency virus infection. J Korean Med Sci 28: 374-377.

32. Molaeipoor L, Poorolajal J, Mohraz M, Esmailnasab N (2014) Predictors of tuberculosis and human immunodeficiency virus co-infection: A case-control study. Epidemiol Health 36: e2014024. 